\title{
Urdimento
}

Revista de Estudos em Artes Cênicas

E-ISSN: 2358.6958

\section{Um espaço de emergência: Herdeiras de Antígona como imantação social e política}

Lígia Souza Oliveira

Francis Wilker

\section{Para citar este artigo:}

OLIVEIRA, Lígia Souza; WILKER, Francis. Um espaço de emergência: Herdeiras de Antígona como imantação social e política. Urdimento, Florianópolis, v. 2, n. 38, ago./set. 2020.

DOI: http:/dx.doi.org/10.5965/14145731023820200019

Este artigo passou pelo Plagiarism Detection Software | iThenticate 
Um espaço de emergência: Herdeiras de Antigona como imantação social e política

\author{
Lígia Souza Oliveira ${ }^{1}$
}

Francis Wilker ${ }^{2}$

\begin{abstract}
Resumo
O presente artigo se dedica a pensar as relações entre as artes da cena e o espaço urbano a partir da intervenção Herdeiras de Antígona (2019), realizada no edifício Copan em São Paulo. A saída de emergência do prédio se dá numa escadaria à vista, e a performance apresenta este espaço como metáfora da urgência dos corpos e dos discursos das mulheres na contemporaneidade. A reflexão proposta é desenvolvida por meio da descrição e análise dessa criação à luz do conceito de espaço imantado encontrado nos escritos da artista visual Lygia Pape. Ao refletir sobre os procedimentos adotados no trabalho, evidencia-se como essa intervenção fez com que os habitantes do lugar trouxessem à tona as tensões sociais e políticas que tem marcado o Brasil desde 2016 e, sobretudo, ecoasse pautas feministas como um espaço de emergência.
\end{abstract}

Palavras-chave: Copan. Espaço imantado. Espaço urbano. Procedimentos de Criação. Releitura de Antígona.

An emergency space: Herdeiras de Antigona as social and political magnetization

\begin{abstract}
This article is dedicated to thinking about the relations between the performing arts and the urban space from the intervention Herdeiras de Antigona (2019), carried out on the Copan building in São Paulo. The emergency exit of the building takes place on a visible staircase, and the performance presents this space as a metaphor for the urgency of the bodies and speeches of women in contemporary times. The osed reflection is developed through the description and analysis of this creation in the light of the concept of magnetized space found in the writings of visual artist Lygia Pape. When reflecting on the procedures adopted at work, it is evident how this intervention made the inhabitants of the place bring to light the social and political tensions that have marked Brazil since 2016 and, above all, echo feminism agendas as an emergency space.
\end{abstract}

Keywords: Copan. Magnetized space. Urban Space. Creation's Procedures. Antigona's Rereading.

1 Profa. Dra. Universidade Federal do Paraná (PR). Desde 2019 coordena o Núcleo de Dramaturgia do SESIParaná. oli.ligia@gmail.com

2 Prof. Curso de Teatro do Instituto de Cultura e Arte da Universidade Federal do Ceará (UFCE). Doutor e Mestre em Teoria e Prática do Teatro pela ECA/USP. Integra o coletivo brasiliense Teatro do Concreto desde 2003. franciswilker@gmail.com 
Un espacio de emergencia: Herdeiras de Antigona como imantación social y política

\section{Resumen}

Este artículo está dedicado a reflexionar sobre las relaciones entre las artes escénicas y el espacio urbano a partir de la intervención Herdeiras de Antigona (2019), realizada en el edificio Copan en São Paulo. La salida de emergencia del edificio se realiza sobre una escalera visible, y la performance presenta este espacio como una metáfora de la urgencia de los cuerpos y discursos de las mujeres en la época contemporánea. La reflexión propuesta se desarrolla a través de la descripción y análisis de esta creación a la luz del concepto de espacio imantado que se encuentra en los escritos de la artista visual Lygia Pape. Al reflexionar sobre los procedimientos adoptados en el trabajo, se evidencia cómo esta intervención hizo que los habitantes del lugar sacaran a la luz las tensiones sociales y políticas que han marcado a Brasil desde 2016 y, sobre todo, se hagan eco de las agendas feministas como espacio de emergencia.

Palabras clave: Copán. Espacio imantado. Espacio urbano. Procedimientos de Creación. Relectura de Antígona. 


\section{Marco zero: o espaço da cidade e suas dimensões}

A reflexão sobre as artes da cena no seu intricado tecer com o tecido urbano demanda a leitura da cidade como um espaço configurado por diferentes aspectos. Afinal, as práticas artísticas, quase sempre, irão atuar exatamente na revelação, tensionamento e friç̧ão com esses aspectos. Antes de melhor descrever a intervenção Herdeiras de Antigona (2019), nos interessa oferecer um ponto de partida para compreendermos a cidade, uma vez que a análise da obra em questão revelará como ela instaurou no espaço um acontecimento que põe em tensão alguns desses aspectos.

Para o historiador Ulpiano Beserra de Meneses (2006) tomar a cidade como objeto de estudo implica examiná-la em múltiplas dimensões e considerando as interações entre essas instâncias. Engajado neste exercício, o autor propõe as seguintes categorias: artefato, campo de forças e representação social. Na sua dimensão de artefato, Meneses focaliza a cidade como objeto construído pelas sociedades, evidenciando a dimensão física do espaço urbano e suas especificidades: "A cidade é coisa feita, fabricada. [...] é a história dos padrões locacionais, das configurações topográficas, dos traçados urbanos e das formas arquitetônicas, dos arranjos espaciais, das estruturas, equipamentos, infinitos objetos." (Meneses, 2006, p. 36).

Ao examinar a cidade como campo de forças, Meneses descreve a segunda dimensão que procura dar ênfase às múltiplas disputas que estão em jogo no espaço urbano.

\footnotetext{
A expressão é tomada de empréstimo à Física, para ilustrar um espaço definível de tensões, conflitos, de interesses e energias em confronto constante, de natureza territorial econômica, política, social, cultural e assim por diante. (Meneses, 2006, p. 36).
}

Podemos identificar tensionamentos diversos, como por exemplo: entre aspectos públicos e privados (como a ocupação de prédios públicos por movimentos de luta por moradia); entre a área do patrimônio histórico e o 
mercado imobiliário (como é o caso do movimento Ocupa Estelita em Recife ou do Parque Augusta em São Paulo); entre bairros nobres e favelas (como no caso do Morumbi e Paraisópolis em São Paulo); entre pessoas em situação de rua e o comércio (presente na maioria das capitais brasileiras); entre demandas feministas e a lógica masculina que rege a cidade etc.

A terceira dimensão apontada por Meneses irá tratar da cidade como representação social.

No entanto, a cidade não é apenas um artefato socialmente produzido, nesse campo de forças, como numa máquina. As práticas que dão forma e função ao espaço e o instituem como artefato, também the dão sentido e inteligibilidade e, por sua vez, alimentam-se, elas próprias, de sentido. Por isso, a cidade é também representação, imagem. A imagem que os habitantes se fazem da cidade ou de fragmentos seus é fundamental para a prática da cidade. (Meneses, 2006, p.36).

Nessa dimensão, encontramos sentidos que ultrapassam as características mais físicas da cidade (artefato) e também das forças e interesses que operam no seu cotidiano gerando múltiplas transformações. Como representação social, outros aspectos emergem quando pensamos no tecido urbano, suas dinâmicas e sobre o sentido de praticar o espaço, habitá-lo e nele conviver com os demais.

As dimensões descritas por Ulpiano Meneses (2006) nos auxiliam a examinar a cidade nos seus diferentes aspectos, todavia, nos parece salutar não as tomar de modo isolado. São dimensões que operam no constante mover, transformação e interação, como a própria vida. As práticas artísticas que se dirigem a composição com os espaços da cidade estão, a todo tempo, fazendo vibrar essa polissemia de aspectos porque se dedicam a propor outras práticas dos espaços; atuam produzindo novos sentidos para o encontro entre nós e determinadas áreas da cidade; mexem/alteram a imagem que temos do lugar em que habitamos coletivamente; não se contentam com as representações dadas do urbano, buscam, muitas vezes, trazer à tona outros discursos e problematizam entendimentos hegemônicos. Pensar um pouco sobre como as artes da cena podem operar nas múltiplas dimensões desse organismo chamado cidade, a partir da obra Herdeiras de Antigona (2019), pode nos oferecer um ponto de vista sobre 
maneiras de colocar em jogo os sentidos e as tensões do espaço habitado.

\section{Escolher um espaço}

Em 14 de abril de 2019 entre 18 h00 e 18 h30 foi realizada a performance Herdeiras de Antígona (2019) na escadaria de incêndio do bloco F do edifício Copan, compondo as ações do projeto 3o ato: o Verso, do Museu do Louvre Pau-Brazyl ${ }^{3}$, na cidade de São Paulo com curadoria de Guilherme Giufrida e Jéssica Varrichio. O convite feito pelos curadores aos artistas participantes foi o de propor uma obra a partir das especificidades do verso (parte de trás) do edifício Louvre. Se pensarmos a cidade como artefato, conforme vimos anteriormente, esse espaço se configura pelo encontro do verso de três edifícios da região (Louvre, Copan, São Luís Plaza) e um terreno baldio entre eles. Esse espaço desocupado é de posse da Universidade de São Paulo, que se negou a participar do projeto ou permitir ações artísticas naquele terreno, o que nos remete ao campo de forças, uma vez que o terreno estava destinado a interesses mercadológicos da instituição. Numa aproximação da dimensão da representação social, aos curadores, aquele "cinturão" de janelas dos apartamentos voltadas a uma mesma área formavam uma espécie de imenso Coliseu no centro da capital paulista. Uma arena em que a vida privada pode ser espiada e onde também a vida pública se tornou um eco recorrente durante as eleições presidenciais de 2018. Segundo eles, era comum gritos pelas janelas como o "Ele não" ou "Fora PT", reverberando as preferências políticas dos moradores.

Para quem está em algum apartamento no verso do edifício Louvre, tem-se um encontro revelador com a arquitetura imponente do edifício Copan na composição da paisagem.

${ }^{3}$ O projeto artístico-curatorial foi criado em 2016 por Guilherme Giufrida e Jéssica Varrichio. Seu ponto de partida foi pensar o edifício onde moram, o Louvre em diálogo com o próprio museu francês e as filiais que abriu em outros países. Assim, o projeto ao mesmo tempo é uma ironia com essas filiais e um espaço de pensar as especificidades do edifício projetado pelo paulistano João Artacho Jurado na década de 1950. 
Figura 1 - Vista do edifício Copan e de uma de suas escadarias de incêndio

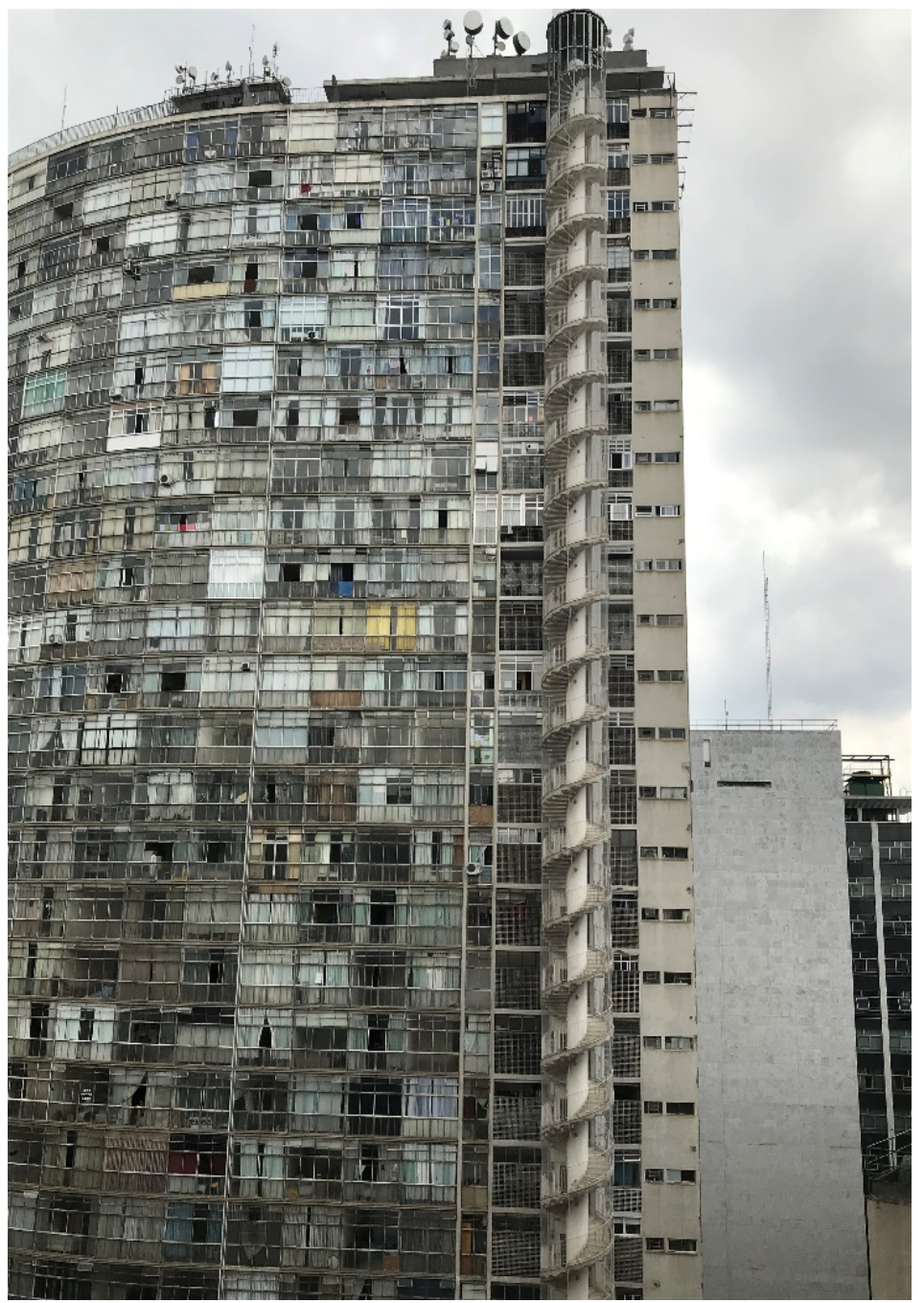

Arquivo pessoal dos autores

O Edifício Copan é considerado um dos prédios mais importantes de São Paulo por se tratar de um ícone da arquitetura modernista e do momento expansionista da cidade. Projetado por Oscar Niemayer, o edifício com 6 blocos possui 32 andares e 1.160 apartamentos de metragens diversas, trata-se da maior estrutura de concreto armado do Brasil.

A escada como uma linha vertical ligando céu e terra entra em contraste com a horizontalidade maciça do prédio e suas janelas que ganham pontos de cor a partir de cortinas, roupas e objetos dos moradores. Daquela primeira experiência paisagística nos interessou o desejo de dar luz à escadaria, de destacá-la como um lugar de fala naquilo que aparentemente parece ser um bloco homogêneo. 
A escadaria que utilizamos é um espaço para emergências, rota de fuga para acontecimentos inesperados. Nesse sentido, o espaço escolhido se tornou o conteúdo do que gostaríamos de abordar na performance. Ao realizarmos as ações na rota de emergência do prédio, reforçamos a emergência também dos corpos ali presentes, das falas ali proferidas e dos gestos que ecoaram na visualidade do espaço. A emergência do espaço foi uma metáfora também para a emergência das mulheres, a emergência de seus discursos, de suas histórias, de suas vidas.

\section{Provocar novas vistas e sentidos para um espaço}

Na perspectiva temática, o Brasil viveu em 2018 uma polarização política radical nas eleições para presidente, e as mulheres se posicionaram como principal resistência à pauta de Jair Messias Bolsonaro, convocando marchas em todo o país. Muito sensibilizados pela percepção desses corpos femininos como linha de frente do lema "Ele não", procuramos percorrer a história ocidental e também o imaginário feminino construído ao longo dos anos, nos perguntando sobre outras mulheres que enfrentaram o Estado, o poder, e que pagaram alto preço por sua coragem. Essa reflexão nos levou a Antígona, personagem da tragédia grega de Sófocles provavelmente escrita no ano de 442 antes de Cristo. Porém, nossa herança não é somente ocidental. Somo, sobretudo, um país erguido pelas mãos de pessoas negras que foram violentamente escravizadas. Nos lembramos então de Dandara, a liderança negra num Brasil-colônia que lutou por sua gente e da qual tão pouco se sabe. Por fim, acessamos também nosso mito mais contemporâneo, a socióloga, vereadora e ativista Marielle Franco, brutalmente assassinada no Rio de Janeiro, crime que segue impune ainda hoje. Além disso, a ação também fazia alusão ao alto índice de feminicídios no Brasil. A partir dessas conexões de uma linhagem de mulheres pensamos a ação na escadaria que se configuraria como um coro feminino distribuído nos andares. Vozes urgentes a ocuparem um espaço da emergência.

A pesquisa realizada sobre a tragédia de Antígona abriu muitas pontes para o trabalho. São vários os estudos e reflexões que desdobram as questões feministas 
na obra, que ainda hoje se mostra tão atual. No enredo, Antígona enfrenta o governo estabelecido por acreditar que as leis dos homens (lei da polis) estão se sobrepondo à lei dos deuses (lei do óikos) por um capricho do rei Creonte. Após o confronto entre os dois irmãos de Antígona, e a morte de ambos, o rei decidiu punir o irmão que iniciou a guerra com a sentença de que ele não fosse enterrado. $\mathrm{Na}$ lei dos deuses todo ser humano tem direito aos rituais sagrados de sepultamento. Ao negar essa possibilidade, Creonte vai de encontro às crenças de toda uma tradição. É então que, Antígona, ao enfrentar o estado e enterrar o irmão, ganha a sentença de morte: ser enterrada viva.

O chamado que recebemos da obra de Sófocles foi justamente no movimento de denunciar o feminicídio. Ainda hoje mulheres são mortas por enfrentar uma sociedade que legitima o machismo e impõe à mulher um lugar de silenciamento. No sentido atual, enfrentar a lei da polis é enfrentar a lógica patriarcal que invade tanto as relações na ordem do social como do privado. 0 enfrentamento começa, principalmente, dentro de casa.

Com isso, a tragédia de Antígona se mostrou fundamental para pensarmos a ação. Convidamos cerca de 20 mulheres $^{4}$, de diferentes áreas como o Teatro, a Terapia Ocupacional, Psicologia, Educação para, assim como a personagem grega, enfrentarem a ordem imposta e o silêncio perante as ações indicativas dos poderes hierárquicos. Esse é exatamente o movimento de Antígona, em nome de suas divindades, enfrentar o poder estabelecido e se colocar diante de tiranias. Neste chamamento à ação no século XXI, essas mulheres-performers se recolocam frente às suas divindades e evocam Dandara e Marielle como ancestrais que propõem uma nova relação consigo mesmas: as leis não as limitam mais, ao contrário, as libertam.

Portanto, no processo encontramos dois desejos: (1) explorar a temática da luta feminina diante do poder estabelecido e (2) experimentar e experienciar o espaço público/privado dos fundos do Edifício Copan.

${ }^{4}$ Adriana Guerra, Andréia Martinez, Camila Freire, Cynthia Margareth, Débora Lima, Fernanda Lellis, Flaviana Benjamin, Goretti Albuquerque, Jéssica Varrichio, Julia Monteiro, Júlia Teixeira, Juliana Birchal, Lanna Carvalho, Mariela Lamberti, Mônica Pellegrini, Nati Flora, Sofia Boito, Thaís Beiral e Thaline Furtado. 


\section{Procedimentos de composição com o espaço}

Este projeto colocou novos desafios para nós, os artistas-idealizadores: lidar com uma escala arquitetônica muito ampla; escassos recursos financeiros para a realização da ação; a necessidade de envolver um grande número de performers, e outros. Entre testes e experimentos, nossa conclusão foi a de lidar com a iluminação e a sonoridade para ativar o espaço. De algum modo, seria como jogar som e luz na escadaria para potencializar sua presença na paisagem.

Cerca de 20 mulheres compuseram um coro que teria um roteiro de ações, envolvendo: chamar pelos nomes de Antígona, Dandara e Marielle em momentos distintos; usar apitos; aplaudir; usar um letreiro luminoso formando duas frases ao longo da ação (Somos Muitas; A luta não dorme); manipular objetos luminosos, como guirlandas de luz e outras. Além disso, desenvolvemos um texto que foi impresso e distribuído em cada apartamento do bloco posterior do edifício Louvre, uma escrita que conectava aquilo que acontecia na escadaria com o nosso horizonte de sentidos 5 .

A equipe envolvida, artistas propositores, performers participantes e assistentes de produção ${ }^{6}$ se reuniu cerca de duas horas antes do início previsto do acontecimento. Na oportunidade, todas as pessoas se apresentaram, debateram a proposição temática a partir da tragédia de Antígona, repassaram o roteiro de ações, distribuíram e testaram os materiais que seriam utilizados e discutiram a importância da sincronicidade dos gestos, afinal, tratava-se de uma coralidade. O principal recurso para ajudar a criar a sincronia foi ajustarmos os relógios, desse modo, estávamos todos marcando igualmente a passagem do tempo. Além, disso, um dos artistas se posicionou na cobertura do edifício Louvre, de onde tinha a visão completa de toda a escadaria de incêndio do Copan e poderia fazer direcionamentos, por meio do WhatsApp, aos três assistentes de produção

\footnotetext{
A carta e outras informações sobre a performance estão disponíveis no site www.lalettre.art.br/herdeirasdeantigona

6 Douglas Teixeira, Gabriel Dantas e Júnior Cecon.
} 
que estavam prestando suporte às performers, de modo que cada um cuidava de mais ou menos 7 lances de escada. Exemplo de instruções dadas durante a realização foi alguma performer se esquecer de ligar a luminária do cartaz ou se posicionar numa zona da escada que não tinha muita visibilidade, a partir do contato o assistente se dirigia rapidamente ao andar indicado e dava as instruções à performer.

Figura 2 - Frase "A luta não dorme" iluminando a escadaria

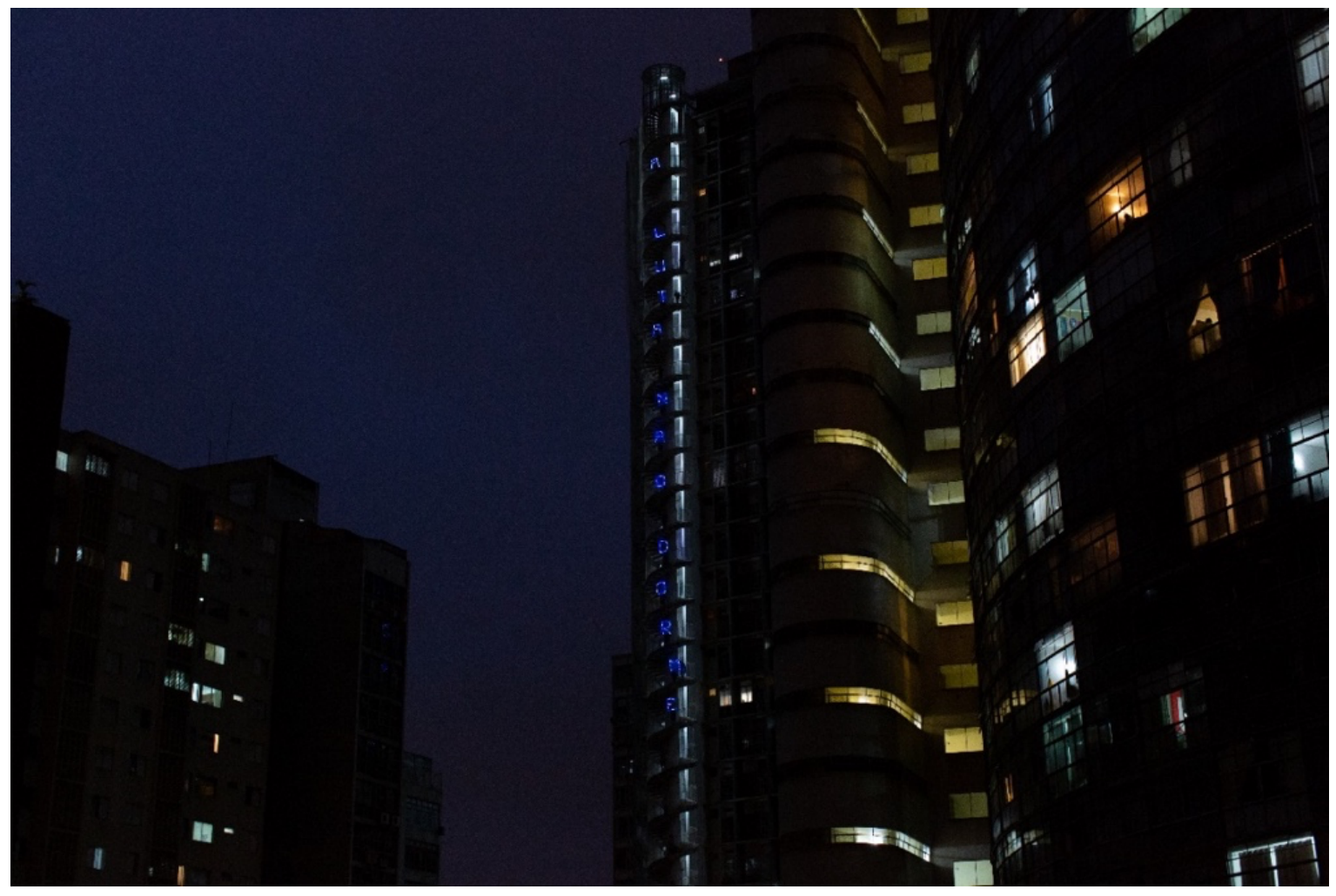

Foto: P. Ardid

Ao longo da ação, os moradores-espectadores participaram espontaneamente de muitos modos, fosse gritando em convergência aos temas da performance, fosse em contraposição a eles. Uma voz masculina grita: Cala a boca! Depois de certo tempo da instauração da ação, alguns moradores reverberam as tensões políticas do país em gritos como: Lula livre, Bolsonaro, Sergio Moro, o Lula tá preso seu babaca etc. Um dos momentos mais impactantes da ação foi quando o coro de mulheres começou a invocar Marielle, chamando pelo seu nome. Como uma onda a ressoar, vozes dos prédios do entorno se 
alastraram gritando junto. Marielle tornava-se ali um nome escrito com som no vento. Um eco.

Uma outra participação inesperada dos espectadores-moradores se deu nos momentos finais da performance. Na parede de um edifício foi projetada por alguém, os nomes das mulheres invocadas: Antígona, Dandara e Marielle. Esse conjunto de reações nos remete à potência de imantação do espaço que uma proposta artística pode ativar, como se Herdeiras de Antigona, por meio das ações das performers, criasse uma espécie de teia em que os moradores e moradoras da região puderam se embaraçar, criando um espaço imantado.

Figura 3 - Projeção de autoria não identificada

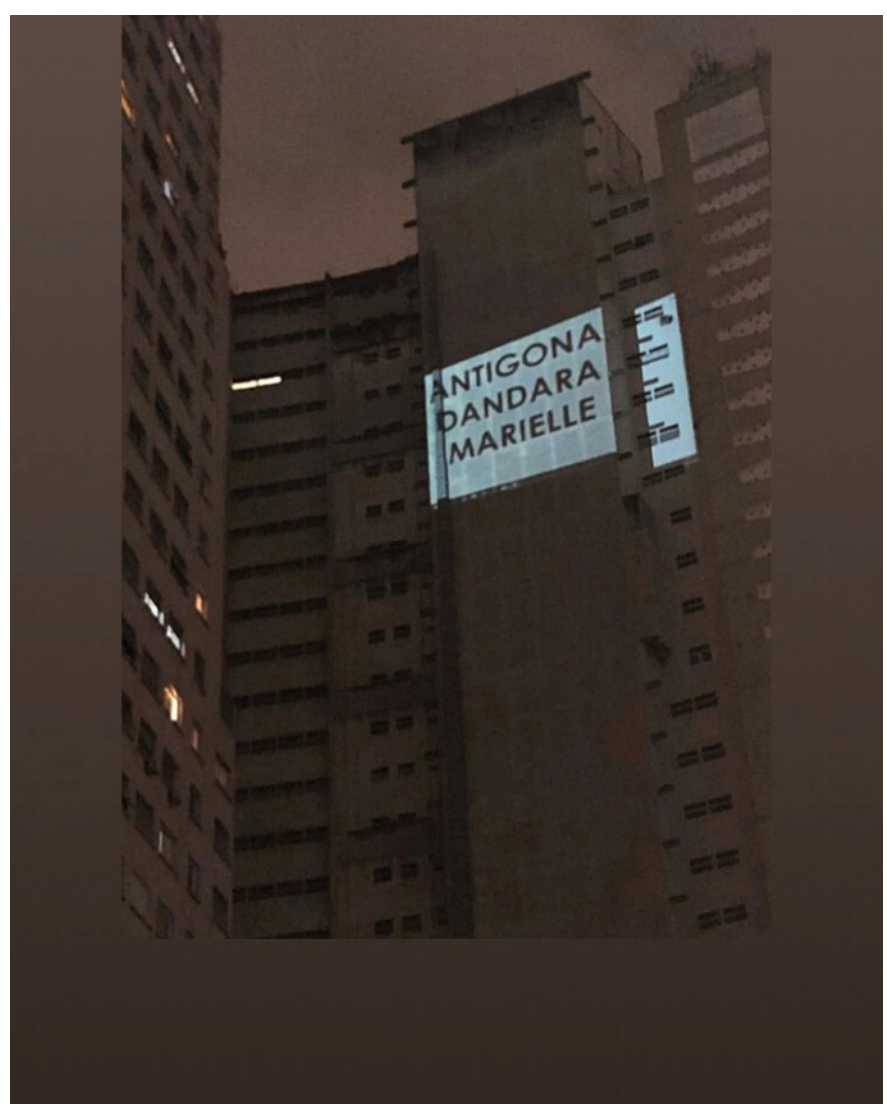

Foto: João Dias Turchi

\section{Herdeiras de Antígona como imantação do espaço}

A noção de espaço imantado, proposta pela artista visual Lygia Pape, nos 
interessa numa aproximação com Herdeiras de Antigona inicialmente por duas razões: 1) considera o envolvimento do outro na tessitura do acontecimento; 2) demonstra como as ações de um indivíduo pode gerar aproximações e distanciamentos com outros corpos no espaço, como fica evidente na descrição e imagens escolhidas por Pape na sua descrição:

A partir de minhas andanças de carro pela cidade - porque eu ando muito de carro - fui percebendo um tipo novo de relação com o espaço urbano, assim como se eu fosse uma espécie de aranha tecendo o espaço, pois é um tal de vai daqui, cruza ali, dobra adiante, sobe e desce em viadutos, entra e sai de túneis, eu e todas as pessoas da cidade, que é como se passássemos a ter uma visão aérea da cidade e ela fosse uma imensa teia, um enorme emaranhado. E eu chamei de espaços imantados porque aquilo tudo era uma coisa viva, como se eu fosse caminhando ali dentro a puxar um fio que se trançasse e se envolvesse ao infinito. E o camelô também seria uma forma de espaço imantado, no sentido de que ele chega assim numa esquina, abre aquela malinha e começa a falar, criando de repente uma imantação, com as pessoas todas se aproximando, se ligando àquele discurso irregular, às vezes, curto, às vezes longo, e de repente ele fecha a boca, fecha a caixinha e o espaço se desfaz.

E tem também outros espaços que eu considero como espaços imantados naturais, com é o caso da Baixada Fluminense, que é um espaço agressivo, terrível, furioso, desesperador e belo. [...] Assim como na Rua da Alfândega, onde você capta imediatamente toda uma poética própria. (Pape in Herkenhoff, 2012, p. 285).

A partir da metáfora dessa aranha que tece o espaço, que puxa um fio que se vai trançando, poderíamos pensar nas performers de Herdeiras de Antígona durante sua ocupação na escadaria de incêndio do edifício Copan. O que essas aranhas-performers realizavam com seus corpos produzia uma imantação daquele espaço que atraía outros corpos a se dirigirem para as janelas de seus apartamentos e também lançarem seus fios, como se aquele espaço - feito um ímã - os puxasse.

Ao referenciar o camelô, Lygia Pape nos mostra como é a ação do seu corpo que produz a imantação do espaço, (chega, abre a malinha, começa a falar). Nesse sentido, uma ação simples, um convite, também pode contribuir para imantar os 
espaços. Acreditamos que é no agir desses corpos no espaço que se forma o que poderíamos chamar de um "campo magnético".

Pape também nos indica que existem "espaços imantados naturais". São localizações que por si só são propositores de aderência física e principalmente imaginária: aspectos arquitetônicos, história do lugar, fluxos, funcionalidades ou usos, etc.

No caso da performance em análise, se as ações das performers na escadaria operariam na lógica da imantação daquele espaço, nos motivou pensar também possibilidades de imantar os apartamentos do edifício Louvre que estão voltados para a escada de emergência do Copan, moradores que teriam uma visão privilegiada daquela ação.

Nesse sentido, na tentativa de mobilizar outros olhares para o lugar conhecido, de criar um campo magnético invisível entre aquilo que ocorria na escadaria e os/as habitantes, redigimos uma carta propondo um engajamento dos moradores do verso do Edifício Louvre. Além de divulgar a ação que aconteceria no fim da tarde, a carta atuaria como uma espécie de convite ao olhar, direcionando de maneira ora objetiva, ora poética as ações que aconteciam na escadaria, a teia de nossa performance alcançaria outros espaços e afetaria esses corpos de uma maneira diferente.

A carta inicia com uma orientação sugestiva: "Já dizia a poeta Ana Cristina César que uma carta não é só poesia. Uma carta é um desejo de um olhar de alguém, um desejo de mobilizar alguém. Uma carta é também um convite." (Oliveira e Wilker, 2019).

Após esse trecho, há uma construção semelhante ao roteiro de ações que foi distribuído às performers: a cada nova ação na escadaria do Copan, um convite à fruição. Dessa forma, também o espectador possui um roteiro de ações para ser executado com os olhos e os ouvidos. A carta foi construída indicando o decorrer das horas no período da performance. A ação iniciava com as batidas do sino da Igreja da Consolação, que podia ser ouvido dos prédios. Em seguida, as performers gritavam o nome de Antígona. Com isso a carta iniciava também um diálogo com 
a cidade:

18 h00 - Os sinos da igreja tocam. Por quê? Um nascimento? Uma celebração? Um pesar? Uma morte? Quem morreu? Ao longe escutamos uma voz. Ouvimos da janela de nossos apartamentos... 18h01 - Uma mulher. É voz de uma mulher. Muitas mulheres. 18h02 - Você ouve os gritos? São gritos! Um chamado. Essas vozes femininas também procuram encontrar outras mulheres. (Oliveira e Wilker, 2019).

Além disso, o texto também propunha outras formas de relação com a ação na escadaria, indicando informações da nossa realidade que atravessam completamente as ações das mulheres artistas: "18h13 - Desde que começamos esta carta, duas mulheres já foram estupradas no Brasil. [...] 18 h16 - Silêncio (impossível)." (Oliveira e Wilker, 2019).

A carta também direcionava o olhar dos espectadores para as ações da escadaria para além da sua visualidade e sonoridade, mas também para a sua coautoria, seu engajamento. Enquanto as performers construíam com letreiros a frase A Luta não dorme, havia a seguinte orientação na carta: "18h15 - Antígona e Dandara nos dizem o que devemos fazer. Você consegue ler pela janela do seu apartamento? É um conselho. Nossa única escolha. É também um convite." (Oliveira e Wilker, 2019).

Dessa forma, a composição desta carta-teia acaba por desembocar em duas resultantes. Por um lado, o texto, ao ser lido concomitante com a performance, traz texturas diversas para a fruição do morador/espectador além de colocá-lo de forma ativa na composição total da obra. Ao ler a carta, ele também cria uma ação do olhar em direção às ações da escadaria do edifício Copan. Por outro lado, temos a proposição de Herdeiras de Antígona adentrando o espaço privado. Um texto criado para a performance também possui sua autonomia, é como se todas as ações indicadas na carta fossem realizadas diariamente a cada vez que alguém a lesse, afinal, assim como a morte de mulheres, a sua luta também é cotidiana. 


\section{Herdeiras de Antígona e seus planos de imantação}

Quando analisamos a performance Herdeiras de Antigona inicialmente podemos associá-la a uma característica muito similar ao que poderíamos indicar nos espaços teatrais convencionais: o público, no seu lugar confortável, assiste às ações no espaço que não demanda um engajamento físico de percurso pelo espaço ou de deslocamento para ambientes não convencionais. Vê-se tudo da segurança de sua casa. Se nos acercarmos um pouco mais da experiência, podemos entrever outras nuances: os moradores e moradoras de cada apartamento dos prédios vizinhos não escolheram um espetáculo em cartaz na cidade e se organizaram para ir ao seu encontro. Não se mostra presente o pacto inicial entre os corpos que ocupam a plateia e aqueles que ocupam o palco. Desse modo, a ação artística que se inscreve em composição com aquele espaço, gera, como vimos, uma imantação que desloca as dinâmicas habituais. Ações costumeiras como assistir à TV ou preparar um lanche na cozinha ganharam outros atravessamentos por meio das ações das performers, como por exemplo, rememorar o assassinato da ativista negra Marielle Franco e tudo que ele significa. Assim, o trabalho oferece aos moradores uma outra vista daquilo que salta de sua janela, em síntese, uma paisagem reconfigurada. Como sugere a artista visual Karina Dias (2010) "a paisagem cotidiana se origina de uma experiência do espaço rotineiro, do momento em que the conferimos um novo sentido. O que desencadearia uma tomada de posição, uma tomada de posse sensível." (Dias, 2010, p.294).

Dessa forma, podemos fazer um paralelo muito proveitoso em relação à experiência em Herdeiras de Antígona. Indicamos três espaços imantados em convivência nesse acontecimento. Por um lado, o olhar dos moradores/espectadores dos diferentes edifícios atua como uma criação de teias imaginárias em direção à escadaria do Edifício Copan. Já os moradores que receberam a carta (edifício Louvre), tiveram acesso a uma espécie de janela textual que oferecia novos vetores de sentido para a sua relação com aquilo que ocorria através de suas janelas de vidro. É o olhar que traça rotas e proporciona 
magnetismos no espaço entre os edifícios. Por outro lado, as ações das mulheres funcionam como propositoras de magnetismos, trazem o lugar à fala. Sons diversos, gritos, frases esculpidas ao longo do prédio são chamamentos, que proporcionam aglomerações nas janelas, tais quais um camelô no centro das cidades. É emanado um campo magnético a partir das ações dessas mulheres performers. Mas também, por fim, há a consciência de que o espaço entre os três edifícios já carrega em si um "espaço imantado natural” haja vista a quantidade de ações que os próprios moradores já realizavam anteriormente à performance. Portanto, ao encontrarmos a projeção sem autor identificado durante a performance, reconhece-se que já há ali previamente uma instauração de um espaço público/privado de discussão de questões sociais.

Por fim, salientamos que o espaço também é invadido pela figura feminina. A possibilidade de discutir o espaço público e o privado também se deu na construção de uma poética da mulher. As vozes que partem de um espaço privado (no caso o Copan) invadem o público numa sonoridade que é política e ética ao mesmo tempo: as sonoridades femininas saem do particular e alcançam o público. Por outro lado, a voz feminina também invadiu o privado, o individual. Ao propormos a escritura de uma carta as palavras que dialogam com as ancestrais escolhidas, Antígona, Dandara e Marielle, convidam ao olhar e à escuta do público. As palavras, na construção poética da performance, explodem o espaço físico da ação e se dissolvem no imaginário de quem as lê, mesmo que à posteriori. Ou seja, espaço poético e espaço real se transmutam mutuamente no percorrer da performance. A mulheres se modificam, modificam o imaginário dos espectadores e modificam o espaço público e privado na tentativa de deslocar, transformar ativamente a nossa realidade.

\section{Considerações finais}

O percurso tecido em nossas reflexões procurou examinar a performance Herdeiras de Antigona dando ênfase em duas questões: as estratégias de composição que procuraram mobilizar outros modos de relação dos espectadores 
com a paisagem cotidiana e a ocupação de um espaço da cidade por mulheres como um dispositivo capaz de friccionar as lógicas que regem as próprias dinâmicas do espaço urbano. Retomando as dimensões da cidade propostas por Ulpiano Meneses (2006), apresentadas no início deste texto, numa aproximação mais direta com a performance realizada, podemos identificar a interação entre sua face artefato, campo de forças e representação social.

Na dimensão do artefato, de pensar a cidade e seus fragmentos como coisa construída, temos a própria arquitetura do edifício Copan tomada como elemento de composição da ação artística. Além disso, a topografia do terreno e o desenho que a disposição dos prédios inscreve na geografia do centro de São Paulo evocou a ideia de um coliseu, presente nas formulações da curadoria do projeto e explorada na ação proposta pelos artistas na medida em que a escadaria escolhida poderia criar uma relação com as diferentes janelas daquele conjunto de edificações. Se não existisse aquele terreno vago entre os edifícios, certamente seria outro o desenho do espaço e as possibilidades de jogo com essas características encontradas no lugar.

Ao nos acercarmos da experiência na dimensão do campo de forças, parece evidente como a ação provocou uma necessidade de expressão de pontos de vista de diferentes moradores acerca daquilo que acontecia e das temáticas ativadas pela performance. Se como nos lembra Meneses (2006), operam na cidade diferentes forças em permanente conflito, as tensões sociais e políticas também se inscreveram no campo magnético criado por Herdeiras de Antigona. Cada grito daquelas janelas eram representantes de determinados modos de pensar um projeto não apenas de cidade, mas, de país. Uns, mais alinhados a uma perspectiva autoritária, masculina, ordeira, nacionalista, para os quais a ação parece ter soado como uma espécie de provocação. Para outros, que se identificaram com as demandas lançadas pelo coro de mulheres, as ideias de igualdade e garantia de direitos e, sobretudo, a atitude de enfrentamento diante da marcha conservadora que tomou o governo, talvez, tenha funcionado como uma enzima catalisadora que ampliava na paisagem a ressonância dos temas que thes importavam.

No que se refere a dimensão da representação social, em que as práticas dão 
sentido à cidade e aos seus fragmentos, poderíamos dizer que o diálogo composicional com a estrutura vertical de concreto, por alguns instantes, se transformou, ganhou a voz de quase vinte mulheres, foi símbolo da emergência de suas lutas e da defesa de suas vidas. Uma ação artística que possibilitou aos espectadores-moradores outros elos sensíveis com o espaço, a construção de outra cartografia do seu ambiente habitado. Fundou, ainda que de maneira efêmera, uma nova imagem daquele local e the atribui novos sentidos.

\section{Referências}

DIAS, Karina. Entre visão e invisão: paisagem: por uma experiência da paisagem no cotidiano. Brasília: Programa de Pós-Graduação em Arte, Universidade de Brasília, 2010.

MENESES, Ulpiano Beserra de. "A cidade como bem cultural - áreas envoltórias e outros dilemas, equívocos e alcance da preservação do patrimônio ambiental urbano". In: Mori, V.H [et. al.] Patrimônio: atualizando o debate. São Paulo: 9.SR/Iphan, 2006. p.35-76.

OLIVEIRA, L.S e WILKER, F. Carta Herdeiras de Antigona. Disponível em www.lalettre.art.br/herdeirasdeantigona. Acesso em: 20 ago. 2020.

\section{CATÁLOGO DE EXPOSIÇÃO}

PAPE, Lygia. Espaço Imantado. Textos de Paulo Herkenhoff; Manuel J. Borja-Villel. São Paulo: Pinacoteca do Estado de São Paulo, 2012.

Recebido em: 01/07/2020

Aprovado em: 22/08/2020 